\title{
ALK-positive anaplastic large cell lymphoma with soft tissue involvement in a young woman
}

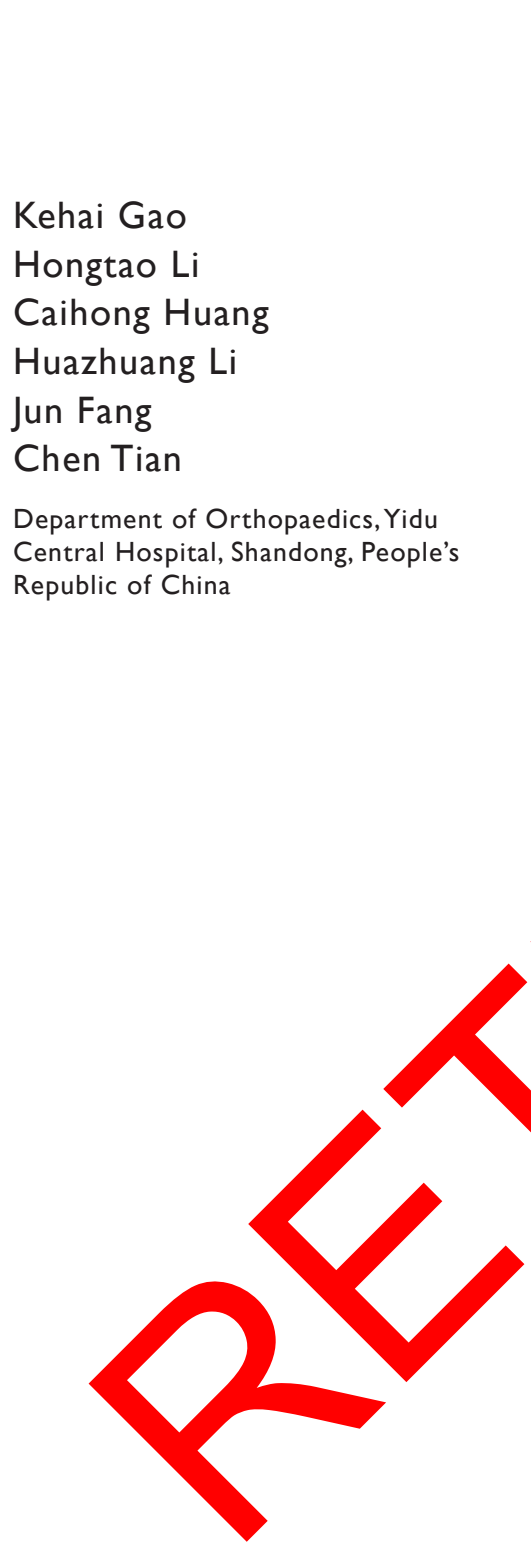

\section{Case}

Correspondence: Kehai Gao; Chen Tian Department of Orthopaedics, Yidu Central Hospital, Renmin Street, Qingzhou, Shandong, 26I04I, People's Republic of China Email kehaigao222@sina.com; spi_2004@126.com I July 2016
This article was published in the following Dove Press journal: OncoTargets and Therapy

Number of times this article has been viewed

Introduction: Anaplastic large cell lymphoma (ALCL) is a typ 'non-Hodgki ymphoma that has strong expression of CD30. ALCL can sometimes iv sve the b marroy and in advanced stages, it can produce destructive extranodal lesion sut anapstic la (ALK)+ ALCL with soft tissue involvement is

Case report: A 35-year-old woman preser a with pain for er 1 month. The biopsy of soft tissue lesions showed that these cell positive fo U , CD30, TIA-1, GranzymeB, CD4, CD8, and $\mathrm{Ki} 67(90 \%+)$ and neg ave for P3, CD5, CD 0, CD10, cytokeratin (CK), TdT, HMB-45, epithelial membrane antiren (EMA), a van-CK, which identified ALCL. After six cycles of Hyper-CVAD/MA gimen, she achieved, artial remission. Three months later, she died due to disease progres on.

Conclusion: This case illust s the unusual esentation of ALCL in soft tissue with a bad response to chemotherapy. Recause of th ndency rapid progression, ALCL in young adults with extranodal lesions are ten with ninn-grade chemotherapy, such as Hyper-CVAD/MA.

Keywords: anapla ic lar anphoma, ALK+, soft tissue involvement, Hyper-CVAD/MA Ir rod trion

988. sifica n, and is nowadays classified as a non-Hodgkin lymphoma of T-cell origin by the Wor Health Organization with strong expression of CD30. ${ }^{1,2}$ ALCL is common Asian countries, which can be divided into three separate groups with different progn s: anaplastic large cell lymphoma kinase (ALK)-positive ALCL, ALK-negative ALCL, and primary cutaneous ALCL. Systemic ALCL has an aggressive clinical course, and patients frequently present with systemic symptoms, advanced-stage disease, and extranodal localizations. ${ }^{3,4}$ Response to treatment and overall survival of systemic ALCL in children are good. In adults, however, it is not clear. ALCL sometimes can involve the bone marrow, and in advanced stages, it can produce destructive extranodal lesions. But ALK+ ALCL with soft tissue involvement is very rare. Here, we report a case of ALK-positive ALCL with soft tissue involvement in a young woman.

A 35-year-old woman who presented with waist pain for over 1 month was examined in our hospital. The patient had no fever or weight loss. Physical examination revealed hepatosplenomegaly and a lump in the waist but no lymphadenopathy. Serum lactate dehydrogenase was elevated to 1,500 IU/L (normal 200-460 IU/L), and other laboratory data showed anemia. ${ }^{18} \mathrm{~F}$-fluorodeoxyglucose (FDG) positron emission tomography (PET) scanning showed that accumulation of FDG was observed in the 



Figure I PET-CT of the patient.

Notes: (A) CT of the patient. (B) PET of the patient. (C) PET-CT of the patient. (D) Multum in pr

Abbreviations: PET, positron emission tomography; CT, computed tomography; L, left; R, ri

soft tissue lump near the lumbar vertebra $1-5$, considering malignant tumor (Figure 1). PET-computed tomograp (CT) also showed many FDG-avid mass in mediastinu and mesenterium, suggesting lymphatic metastasis. A CT guided biopsy of soft tissue lesions revealed $A$ These cells were positive for ALK-1, CD30, TIA Granz heB, $\mathrm{CD} 4, \mathrm{CD} 8$, and $\mathrm{Ki} 67(90 \%+)$ and negative $\mathrm{C}$, Comen CD20, CD10, cytokeratin (CK), Td HMB-4 epithelial membrane antigen (EMA), and $\mathrm{An}$ (Figure Bone marrow aspiration and trephin bropsy sho d no infiltration. She was diagnosed as AI positive ALCL th soft tissue involvement. After twe ycles of yper-CVAD/MA chemotherapy, her condition S. Wo signi cant improvement. After four cyg Hyp CVA MA chemotherapy, she achieve partiall remissto (PR). After six cycles of been initially considered a rare event in ALCL. ${ }^{6}$

Hyp CVAD/M regimen, she still remained in PR. Three month ter al died of disease progression.

\section{Fiscomsion}

Malignant lymphoma with prominent soft tissue involvement is $n$ infrequent, and often diagnostically challenging neoplasm, which represents $\sim 3 \%$ of all primary malignant bone tumors and $1 \%$ of all malignant lymphomas. Among those studies that reported the T- or B-cell phenotype of primary soft tissue lymphoma, B-cell accounted for over $90 \%$. B symptoms such as fever, night sweats, and weight loss, were frequent in ALCL patients. A majority of patients with ALCL had a disseminated disease (Ann Arbor Stage III or IV) and a limited number of extranodal sites. ${ }^{5}$ Bone marrow involvement has
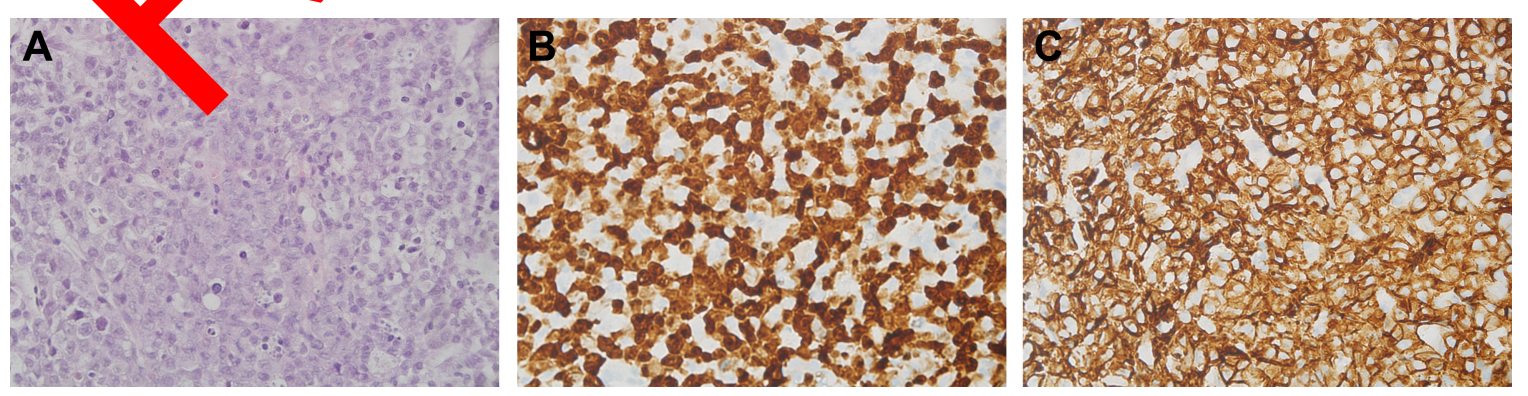

Figure 2 Biopsy of soft tissue lesions: (A) HE staining, (B) ALK staining, and (C) CD30 staining.

Note: Magnification for all images: $400 x$.

Abbreviations: HE, hematoxylin and eosin; ALK, anaplastic large cell lymphoma kinase. 
As ALCL is a highly curable disease, it is important for it to be differentiated from other causes of lytic bone lesions, such as carcinomas and other primary bone tumors. Although this may include cortical or soft tissue invasion, the diagnosis generally excludes lymph node or distant visceral involvement to be considered a primary lymphoma of bone non-Hodgkin's lymphoma (NHL) of bone is a rare entity that is limited to the long bones and axial skeleton, with the femur being the most common site of involvement. Besides, ALCL has to be distinguished from classical Hodgkin lymphoma, $\mathrm{CD} 30^{+}$non-Hodgkin B-cell lymphomas, and very rare ALK-1-positive (and eventually CD30-negative) large B-cell lymphomas.

ALCL is characterized by the expression of CD30 on malignant cells, and its prognosis is related with the expression of the ALK protein. ${ }^{7}$ ALCL is divided into three separate entities based on ALK expression: ALK-positive ALCL, ALK-negative ALCL, and primary cutaneous ALCL. ALCL commonly involves in children and young adults that presents progressive disease with a high incidence of extranodal involvement. ${ }^{8}$ The case we report is ALCL with soft tissue involvement diagnosed with PET-CT, and pathology which is rare. It is known that ALK is an indicator of better responses to treatment in ALCLs. However, this case show complete remission (CR) after six cycles of trea partially because of the soft tissue involvem its response to the treatment. Besides, $C$ o expr sion $m$ reported to link with bad outcomes at m response of this patient.

Although magnetic reson imaging a $\mathrm{CT}$ are the standard imaging modalities or the tection of $\mathrm{KLCL}$ with prominent soft tissue iv olvement, the aging features are usually nonspecifig nd the sion cannotbe fully detected because magnetic - nap rmaging and CT often were performed in a f the PET plays an important role in the dir asis, aging, arveillance of lymphoma.

A. ung $n$ comparative studies have been published, $\mathrm{n}$-nvestigators reported that the response of ALCL to ch otherapy was good, ranging from $60 \%$ to $90 \%$. The overan survival of localized disease is known to be good, especially in children. More advanced stages have a high relapse rate, and their prognosis in comparison to that of other large cell lymphomas is controversial. Because ALCL belongs to NHL, so it is believed that CHOP (cyclophosphamide, doxorubicin, vincristine, prednisone) regimen is generally applicable to ALCL. Besides, modified B-NHL-BFM-90 protocol is shown to be efficacious for Chinese children with ALCL. ${ }^{9}$ It is reported that both autologous and allogeneic hematopoietic stem cell transplantation (HSCT) can offer the prospect of durable disease-free survival for ALCL in childhood and adolescence. Patients with CR at the time of autologous HSCT had significantly greater event-free survival than patients with non-CR at the time of autologous HSCT. ${ }^{10}$ Recently, brentuximab vedotin, which is a CD30-targeted antibody, have emerged. ${ }^{9}$ Novel therapies may soon radically change the treatment paradigm for this disease and hopefully lead to less toxicity and improved outcomes. ${ }^{11}$ In this case, the patient was treated with high-grade chemotherapy, sy row-CVAD/MA. But there was still no significe Improvem $t$ and after six cycles of chemotherapy, she $\mathrm{r}$ achieved $\mathrm{R}$. Then she gave up the treatment 3 died 3 in the 1

\section{Conclusic}

ALCL is a but biolo vally dil-characterized disorder with a v trum of $\mathrm{p}$ - ntation. It may present with soft tissue invol ent. Recognition of a combination of rptorns including emia, renal failure, and bone pain in ne presence normal bone marrow biopsy and serum elecophoresis sh uld trigger aggressive clinical workup to rule o. he pos Ality of lymphoma. A meticulous examination of early oropsies based on PET-CT of deeply situated soft tiss or lymph nodes are recommended to yield an early diagnosis of ALCL.

\section{Acknowledgment}

The subject and her parents/guardians gave their informed written consent, and the study protocol was approved by the Ethics Committee of Yidu Central Hospital.

\section{Disclosure}

The authors report no conflicts of interest in this work.

\section{References}

1. Stansfeld AG, Diebold J, Noel H, et al. Updated Kiel classification for lymphomas. Lancet. 1988;1:292-293.

2. Swerdlow SH, Campo E, Harris NL, et al. WHO Classification of Tumors of Haematopoietic and Lymphoid Tissues. 4th ed. Lyon, France: IARC; 2008.

3. Kadin ME. Primary Ki-1-positive anaplastic large-cell lymphoma: a distinct clinicopathologic entity. Ann Oncol. 1994;5(Suppl 1):S25-S30.

4. Filippa DA, Ladanyi M, Wollner N, et al. CD30 (Ki-1)-positive malignant lymphomas: clinical, immunophenotypic, histologic, and genetic characteristics and differences with Hodgkin's disease. Blood. 1996; 87(7):2905-2917

5. Stein H, Mason DY, Gerdes J, et al. The expression of the Hodgkin's disease associated antigen $\mathrm{Ki}-1$ in reactive and neoplastic lymphoid tissue: evidence that Reed-Sternberg cells and histiocytic malignancies are derived from activated lymphoid cells. Blood. 1985;66(4): $848-858$. 
6. Lowe EJ, Gross TG. Anaplastic large cell lymphoma in children and adolescents. Pediatr Hematol Oncol. 2013;30(6):509-519.

7. Lovisa F, Cozza G, Cristiani A, et al. ALK Kinase Domain mutations in primary anaplastic large cell lymphoma: consequences on NPMALK activity and sensitivity to tyrosine kinase inhibitors. PLoS One. 2015;10(4): $\mathrm{e} 0121378$.

8. Mitou G, Frentzel J, Desquesnes A, et al. Targeting autophagy enhances the anti-tumoral action of crizotinib in ALK-positive anaplastic large cell lymphoma. Oncotarget. 2015;6(30):30149-30164.

9. Amin AD, Rajan SS, Liang WS, et al. Evidence suggesting that discontinuous dosing of ALK kinase inhibitors may prolong control of ALK+ tumors. Cancer Res. 2015;75(14):2916-2927.
10. Fukano R, Mori T, Kobayashi R, et al. Haematopoietic stem cell transplantation for relapsed or refractory anaplastic large cell lymphoma: a study of children and adolescents in Japan. Br J Haematol. 2015; 168(4):557-563.

11. Pillon M, Gregucci F, Lombardi A, et al; NHL committee of the Italian association of pediatric hematology and oncology (AIEOP). Results of AIEOP LNH-97 protocol for the treatment of anaplastic large cell lymphoma of childhood. Pediatr Blood Cancer. 2012;59(5):828-833.

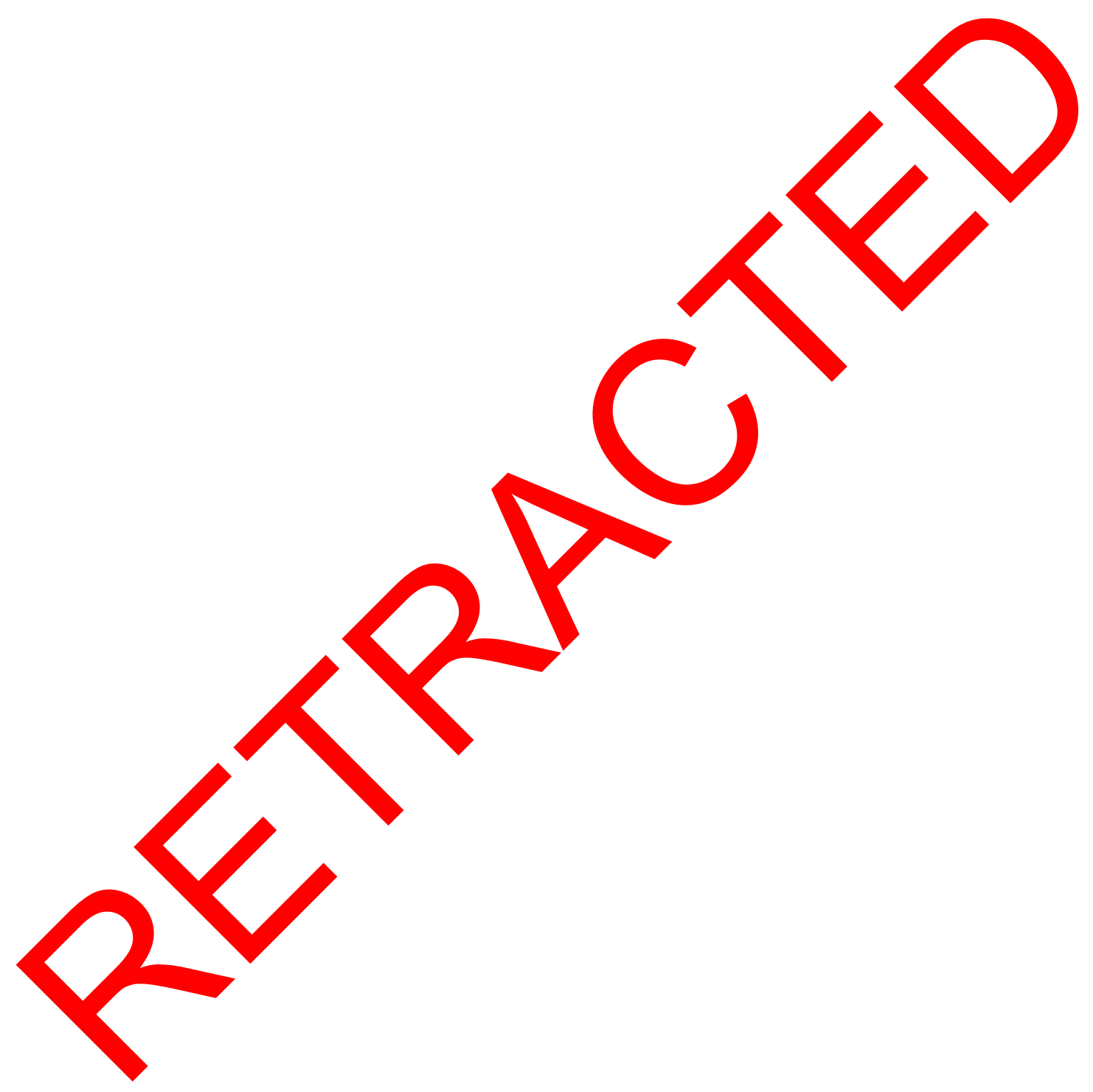

OncoTargets and Therapy

\section{Publish your work in this journal}

OncoTargets and Therapy is an international, peer-reviewed, open access journal focusing on the pathological basis of all cancers, potential targets for therapy and treatment protocols employed to improve the management of cancer patients. The journal also focuses on the impact of management programs and new therapeutic agents and protocols on patient perspectives such as quality of life, adherence and satisfaction. The manuscript management system is completely online and includes a very quick and fair peer-review system, which is all easy to use. Visit http://www.dovepress.com/testimonials.php to read real quotes from published authors. 